\title{
APLICAÇÃO DE MODELAGEM NUMÉRICA NO PROGRAMA DE REMEDIAÇÃO DO AQÜÍFERO DO PÓLO CLOROQUÍMICO DE ALAGOAS
}

Manoel de Melo Maia Nobre, $\mathrm{PhD}^{1}$

Rosane Cunha Maia Nobre, $\mathrm{MSc}^{2}$

1 Engenheiro e Consultor da Maia Nobre Engenharia Ltda.

Rua D. Antônio Brandão, 333/609. Maceió, AL

Telefax: (082) 326-3917

2 Professora da Universidade Federal de Alagoas, Dept. de Geociências Br. 104, Km 14 - Maceió - Alagoas

Telefone: (082) 322-2301 